\title{
Kuat Tekan Beton Dengan Menggunakan Agregat Halus Gunung Sugih, Agregat Kasar Sumber Batu Berkah Dan Abu Batu Sumber Batu Berkah Tarahan
}

\author{
Irwan Girinadi ${ }^{1}$, Heri Riyanto ${ }^{2}$ \\ 1,2Teknik Sipil, Fakultas Teknik, Universitas Bandar Lampung \\ Jl. ZA. Pagar Alam No.29, Labuhan Ratu, Kedaton, Bandar Lampung 35142 \\ ${ }^{1}$ girinadi@yahoo.com
}

Intisari - Perkembangan industri konstruksi dan transportasi terus menunjukkan peningkatan yang signifikan seiring dengan peningkatan jumlah manusia beserta kebutuhan manusia itu sendiri. Lampung sebagai provinsi yang berkembang juga dikenai peningkatan tersebut. Bagian konstruksi yang mengalami peningkatan signifikan adalah beton. Kuat tekan beton yang tinggi dengan harga yang terjangkau mulai diteliti dengan melakukan beberapa modifikasi pencampuran memakai bahan tambahan. Salah satu modifikasi tersebut adalah dengan melakukan pencampuran dengan bahan tambahan abu batu. Penelitian ini menjelaskan tentang kuat tekan beton yang pencampurannya menggunakan agregat yang bermutu baik dan bahan tambahan abu batu yang ada di daerah Lampung. Agregat halus yang dipakai merupakan agergat halus alami dari daerah Gunung Sugih sedangkan agregat kasar yang merupakan batu pecah beserta abu batu berasal dari perusahaan pecah Sumber Batu Berkah. Penelitian ini dilakukan di Laboratorium Universitas bandar Lampung. Penambahan abu batu dilakukan secara subtuitusi parsial terhadap $10 \%, 20 \%, 30 \%, 40 \%$ dan $50 \%$ berat agregat kasar dihitung dari gradasi terbesar.Dari hasil penelitian diketahui bahwa kuat tekan yang dihasilkan memiliki nilai kuat tekan rata-rata maksimum pada variasi campuran $30 \%$ yaitu $451,837 \mathrm{~kg} / \mathrm{m} 2$. Kuat tekan rata-rata maksimum pada variasi campuran $30 \%$ ini meningkat kuat tekan sebesar $18,7 \%$ terhadap kuat tekan beton variasi campuran $10 \%$ dan menurun sebesar 6,17\% divariasi campuran abu batu $50 \%$. Berat volume tiap kadar variasi abu batu juga mengikuti hal yang sama. Berat volume terbesar terdapat pada variasi campuran 30\% yang lebih efektif di banding pada variasi $10 \%$ dan mengalami penurunan juga di kadar variasi abu batu $50 \%$.

Kata kunci — Kuat Tekan, Berat Volume, Agregat, Lampung.

Abstract - The development of the construction industry and transportation continue to show a significant increase with the increasing number of people and also the needs of humanity. Lampung province developed as well as an increase in charges. Part of construction that encounter development is concrete. High compressive strength of concrete with an affordable price start to be research to mixing modifications with the use of additive. One of modifications is mixing with stone ash as additive. This research explains about concrete compressive strength which mixed by good quality aggregate and stone ash in lampung area. Fine aggregate that used was natural aggregate from Gunung Sugih while coarse aggregate was crushed stones from Sumber Batu Berkah quarry. This research was done at Laboratory facilty of Bandar Lampung University. The use of stone ash was done in partial substitusion for $10 \%, 20 \%, 30 \%, 40 \%$ and $50 \%$ of coarse aggregate start from the biggest gradation. From the result of this research, the highest compressive strength was discovered in concrete with $30 \%$ use of stone ash which was $451,837 \mathrm{~kg} / \mathrm{m} 2$. The maximum compressive strength was increase about $18,76 \%$ in comparation of $10 \%$ use of stone ash and decreased about 6,17 \% in the use of $50 \%$ ston ash. The density of every level of stone ash use follow the same record of compressive strength. The density weight in $30 \%$ variants use of stone ash which is superior than $10 \%$ and $50 \%$ variants.

Keywords - Compressive Strength, Density Weight, Aggregate, Lampung.

\section{PENDAHULUAN}

Perkembangan industri konstruksi dan transportasi terus menunjukkan peningkatan yang signifikan seiring dengan peningkatan jumlah manusia beserta kebutuhan manusia itu sendiri. Beton sangat diperlukan hampir dalam seluruh kegiatan konstruksi yang ada. 
Peningkatan dalam beton terjadi dalam pemilihan material yang ada, pengolahan dalam proses perencanaan dan pembuatannya, serta aplikasinya dalam beton bertulang, beton prategang, dan jenis-jenis konstruksi lainnya. Bandar Lampung sebagai ibu kota propinsi Lampung juga tidak luput dari perkembangan ini. Berbagai analisa dan kajian terus dilakukan agar proses pengolahan beton dapat semakin mudah dengan material yang ada dan kemudian menciptakan sebuah beton mutu tinggi yang diinginkan. Beberapa metode yang terus disempurnakan seperti metode SNI. Metode ini dapat menciptakan sebuah beton mutu tinggi yang baik jika material yang digunakan adalah material yang baik juga dan memenuhi syarat. Selain penyempurnaan metode yang ada, dilakukan juga beberapa modifikasi dengan menggunakan bahan tambahan, seperti abu batu.

Abu batu merupakan bahan tambahan yang sering dipakai karena bahan ini tergolong murah dibanding bahan campuran lainnya serta mudah didapat. Abu batu juga memiliki berat jenis yang tinggi dan berfungsi sebagai pengisi dengan potensial friksi permukaan yang kasar serta mampu menempati ronggarongga kecil antara material pembentuk beton. Untuk material yang baik di daerah Lampung diambil pasir dari wilayah gunung sugih, agregat kasar dari perusahaan SBB Tarahan, dan semen tipe I atau II. Penelitian ini mencoba memaksimalkan potensi material terbaik di sekitar kota Bandar Lampung untuk dapat diolah menjadi beton mutu tinggi dengan tambahan abu batu. Tujuan penelitian ini adalah mendapatkan nilai karakteristik kuat tekan beton maksimal beton yang berasal dari material yang ada dengan penambahan abu batu pada kadar yang ditentukan.

\section{TINJAUAN PUSTAKA}

Beton adalah material yang dibuat dari campuran agregat halus (pasir), agregat kasar (kerikil), air dan semen Portland atau bahan pengikat hidrolis yang lain yang sejenis, dengan mengunakan atau tidak mengunakan bahan tambah lain. Nilai kuat tekan beton relatif tinggi dibandingkan dengan kuat tariknya, beton merupakan material yang bersifat getas.

Untuk mencapai kuat tekan beton perlu diperhatian kepadatan dan kekerasan massanya, umumnya semakin padat dan keras massa agregat akan makin tinggi kekuatan dan durability-nya (daya tahan terhadap penurunan mutu dan akibat pengaruh cuaca). Untuk itu diperlukan susunan gradasi butiran yang baik. Nilai kuat tekan beton yang dicapai ditentukan oleh mutu bahan agregat ini (Dipohusodo, 1994).

\section{A. Material Penyusun Beton}

Produksi beton yang efektif dapat dicapai dengan mengadakan pemilihan, pengontrolan dan perbandingan yang tepat untuk semua bahan. Untuk melakukan semua kegiatan pracetak di atas, seorang perencana harus mengetahui detil perilaku sifat selurh bahanbahan penyusun beton.

1) Semen Portland

Menurut ASTM C-150 (1985) semen Portland didefinisikan sebagai bahan hidrolik yang dihasilkan dengan menggiling klinker yang terdiri dari kalsium silikat hidrolik yang umumnya mengandung satu atau lebih bentuk kalsium sulfat sebagai bahan tambahan yang digiling bersama-sama dengan bahan utamanya.

\section{2) Agregat}

Heading Penggunaan agregat bertujuan untuk memberi bentuk pada beton, memberi kekerasan yang dapat menahan beban, goresan dan cuaca, mengontrol workability, serta agar lebih ekonomis karena menghemat pemakaian semen.

3) Filler Abu Batu

Penambahan filler yang dimaksudkan untuk meningkatkan kekentalan beton. dalam penelitian ini dipilih serbuk abu batu karena bahan ini bersifat menyerap air dan mudah didapatkan dengan harga yang murah. Penggunaan serbuk abu batu diharapkan dapat meningkatkan viskositas beton segar sekaligus mengurangi kecenderungan terjadinya 
segregasi dan bleeding pada beton segar, selanjutnya setelah beton mengeras diharapkan serbuk abu batu dapat mengisi rongga-rongga yang ada pada beton sehingga dapat meningkatkan kuat tekan beton yang dihasilkan.

\section{4) Air}

Air diperlukan untuk bereaksi dengan semen sehingga terjadi reaksi kimia yang menyebabkan pengikatan dan berlangsungnya proses pengerasan pada beton, serta untuk menjadi bahan pelumas antara butir-butir agregat agar mudah dikerjakan dan dipadatkan. Untuk bereaksi dengan semen, air hanya diperlukan $25 \%$ dari berat semen saja. (Tjokrodimuljo, 1996).

\section{B. Perencanaan Campuran Beton}

Rencana campuran bertujuan untuk menentukan jumlah bagian dari masingmasing bahan, dalam hal semen, pasir dan koral. Perhitungan proporsi beton berdasarkan SNI 03-2834-2000 "Tata Cara Pembuatan Rencana Campuran Beton Normal" ini dipilih karena memiliki faktor perhitungan yang sesuai dipakai di Indonesia serta banyak dipakai secara umum.

Untuk mengetahui kuat tekan beton yang telah mengeras yang disyaratkan, dilakukan pengujian kuat tekan beton. Prosedur pengujian kuat tekan mengacu pada Standart Test Methode for Compressive of Cylindrical Concrete. Langkah-langkah pengujiannya adalah sebagai berikut :

1) Benda uji ditimbang dan dicatat beratnya.

2) Benda uji diletakan pada mesin penekan dan posisinya diatur agar supaya tepat berada ditengah-tengah plat penekan.

3) Pembebanan dilakukan secara perlahanlahan secara continue dengan mesin hidrolik sampai benda uji mengalami kehancuran.

4) Beban maksimum adalah angka terakhir yang dicapai sebelum akhirnya mengalami penurunan.

Kuat tekan beton antara lain tergantung pada : faktor air semen, gradasi batuan, bentuk batuan, ukuran maksimum batuan, cara pengerjaan (campuran, pengangkutan, pemadatan dan perawatan) dan umur beton (Tjokrodimuljo, 1996).

Berdasarkan Peraturan Beton Bertulang Indonesia (PBI, 1989), besarnya kuat tekan beton dapat dihitung dengan rumus :

$$
\mathrm{f}^{\prime} \mathrm{c}=\mathrm{P} / \mathrm{A}
$$

dengan:

$\mathrm{f}^{\prime} \mathrm{c}=$ kuat tekan beton

$\mathrm{P}=$ beban tekan maksimum

$\mathrm{A}=$ luas permukaan benda uji

\section{METODE PENELITIAN}

\section{A. Lokasi dan Peralatan Penelitian}

Pelaksanaan penelitian dilakukan secara eksperimental, di Laboratorium Teknik Sipil Universitas Bandar Lampung. Obyek dalam penelitian ini adalah beton yang menggunakan bahan dasar dari daerah yang memiliki kualitas baik. Sedangkan pengujian kuat tekan dilakukan setelah beton berumur 7 hari. Alatalat yang digunakan dalam penelitian ini adalah : Cetakan Silinder, Oven, Piring Logam, Mesin siever, Ayakan, Timbangan, Gelas Ukur, Ember, Mesin abrasi, Kerucut abrams, Mixer listrik, Sekop, Kaliper, Mesin uji desak, dan Kolam penampungan benda uji. Adapun langkah-langkah penelitian sebagaimana ditunjukkan pada diagram alir Gambar 1 sebagai berikut : 


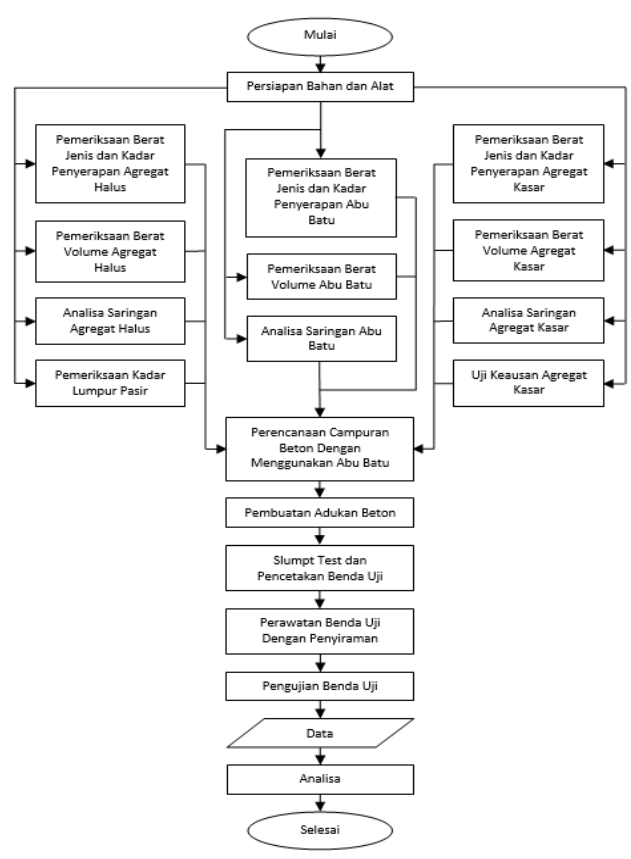

Gbr. 1 Flowchart Metode Penelitian

\section{B. Bahan Penelitian}

Dalam penelitian ini digunakan bahan material berupa semen PCC, air, agregat kasar (batu pecah) dan agregat halus (pasir). Rincian bahan campuran beton pada penelitian ini adalah sebagai berikut :

1) Semen PCC merek Holcim.

2) Agregat kasar dari perusahaan SBB Tarahan dan agregat halus berasal dari wilayah gunung sugih.

3) Air diambil dari Laboratorium Teknik Sipil Universitas Bandar Lampung.

4) Abu batu dari perusahaan SBB Tarahan.

\section{Pelaksanaan Penelitian}

Dalam penelitian ini digunakan bahan material berupa semen PCC, air, agregat kasar (batu pecah) dan agregat halus (pasir). Rincian bahan campuran beton pada penelitian ini adalah sebagai berikut :

1) Pemeriksaan Kadar Lumpur Pasir

Pemeriksaan ini dimaksudkan untuk menentukan kandungan lumpur dalam agregat pasir baik sebelum maupun sesudah mengalami pencucian. Alat yang terpakai antara lain : gelas ukur $250 \mathrm{cc}$, timbangan, air, oven dengan suhu (105-110) ${ }^{\circ} \mathrm{C}$ dan alat tulis.
Kandungan Lumpur $=\frac{100-\left(w_{k 0}-w_{p i}\right)}{100} \times 100 \%$

Keterangan :

Wko = berat kering oven (gram)

Wpi = berat piring (gram)

2) Pemeriksaan Modulus Halus Butir

Pemeriksaan ini bertujuan untuk menentukan pembagian butir agregat kasar dan agregat halus dengan menggunakan saringan urutan ukuran pakai 121",43", 83", no. 4 , no 8 , no. 16 , no 30 , no. 50 , no. 100 , no. 200. (standar ASTM).

3) Pemeriksaan Berat Jenis dan Penyerapan Agregat

Tempat air dengan bentuk dan kapasitas yang pemeriksaan ini dimaksudkan untuk menentukan berat kering permukaan jenuh (SSD) dan penyerapan dari agregat.

4) Pemeriksaan Berat Volume Agregat

Pemeriksaan ini bertujuan untuk mengetahui berat agregat per satuan volume.

$$
\text { Berat volume }=\frac{B_{s}}{v_{b}}-\frac{w_{t a}-w_{t s}}{v_{b}}
$$

\section{Keterangan}

B = berat beton $(\mathrm{kg})$

$\mathrm{Wta}=$ berat tabung silinder berisi agregat

$(\mathrm{kg})$

Wts = berat tabung silinder $(\mathrm{kg})$

$\mathrm{v} \quad=$ volume beton $(\mathrm{m})$

5) Pemeriksaan Nilai Keausan Agregat

Pemeriksaan ini untuk mengetahui besar nilai keausan yang ada pada agregat kasar.

\section{Pengujian Slump}

Pengujian slump dilakukan dengan menggunakan kerucut Abrams, pengujian dilakukan untuk mengetahui tingkat workabilitas dari campuran beton yang telah dibuat. Tabung kerucut Abrams bagian dalam dibasahi dengan air dan disiapkan di atas plat baja. Beton segar dimasukkan ke dalam tabung kerucut dan setiap $1 / 3$ volumenya ditusuktusuk 25 kali dengan penumbuk baja sampai isi 
kerucut Abrams penuh. Beton diratakan permukaannya dan didiamkan selama 0,5 menit, selanjutnya corong kerucut diangkat pelan-pelan secara vertikal tanpa ada gaya horisontal. Tabung kerucut diletakkan di sebelahnya, pengukuran slump dilakukan dari bagian tertinggi beton segar sampai ujung atas kerucut Abrams. Nilai yang didapat merupakan nilai slump, penggambaran dari pengujian nilai slump pada Gambar 2 .

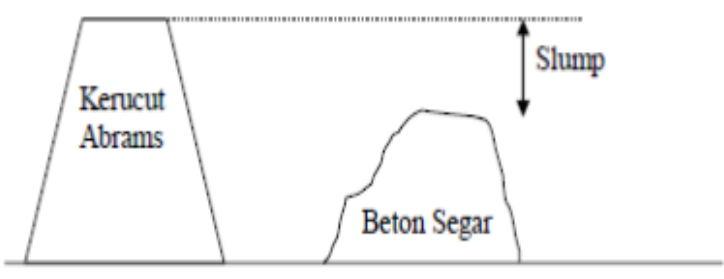

Gbr. 2 Pengukuran Nilai Slump

\section{E. Pembuatan Benda Uji}

Pembuatan campuran beton dalam penelitian ini berpedoman pada metode British 1986. Pembuatan campuran dilakukan dengan molen. Cara pembuatan campuran dimulai dari persiapan bahan dan alat sesuai dengan persyaratan dan kebutuhan material pada saat perhitungan campuran beton (Mix Design).Pada penelitian ini dibuat 25 buah benda uji berbentuk silinder dengan menggunakan cetakan silinder dengan ukuran diameter $15 \mathrm{~cm}$ dan tinggi $15 \mathrm{~cm}$, dengan perincian seperti yang terlihat dalam Tabel 1 .

\begin{tabular}{|c|c|c|c|}
\hline $\begin{array}{c}\text { Kadar abu } \\
\text { batu }\end{array}$ & $\begin{array}{l}\text { Kode } \\
\text { Sampel }\end{array}$ & $\begin{array}{c}\text { Jumlah } \\
\text { Benda } \mathrm{Uji}_{\mathrm{ji}}\end{array}$ & Jenis Benda $\mathrm{Uji}_{\mathrm{ji}}$ \\
\hline \multirow{5}{*}{$10 \%$} & A 1 & 1 & \multirow{25}{*}{ Silinder } \\
\hline & A 2 & 1 & \\
\hline & A 3 & 1 & \\
\hline & A 4 & 1 & \\
\hline & A 5 & 1 & \\
\hline \multirow{5}{*}{$20 \%$} & B 1 & 1 & \\
\hline & B 2 & 1 & \\
\hline & B 3 & 1 & \\
\hline & B 4 & 1 & \\
\hline & B 5 & 1 & \\
\hline \multirow{5}{*}{$30 \%$} & C 1 & 1 & \\
\hline & C 2 & 1 & \\
\hline & C 3 & 1 & \\
\hline & C 4 & 1 & \\
\hline & C 5 & 1 & \\
\hline \multirow{5}{*}{$40 \%$} & D 1 & 1 & \\
\hline & D 2 & 1 & \\
\hline & D 3 & 1 & \\
\hline & D 4 & 1 & \\
\hline & D 5 & 1 & \\
\hline \multirow{5}{*}{$50 \%$} & E 1 & 1 & \\
\hline & E 2 & 1 & \\
\hline & E 3 & 1 & \\
\hline & E 4 & 1 & \\
\hline & E 5 & 1 & \\
\hline \multicolumn{2}{|c|}{ Jumlah Benda Uii } & 25 & \\
\hline
\end{tabular}

\section{F. Perawatan Benda Uji}

Perawatan benda uji ini bertujuan agar permukaan beton segar selalu lembab hingga beton dianggap cukup keras. Kelembaban ini dijaga untuk menjamin proses hidrasi semen berlangsung dengan sempurna.

\section{G. Pengujian Kuat Tekan Benda Uji}

Pengujian dilakukan setelah benda uji mencapai umur 28 hari. Adapun langkahlangkah pengujiannya :

1) Benda uji yang telah mencapai umur percobaan dipersiapkan.

2) Ditimbang untuk mendapatkan data berat silinder beton dalam keadaan kering.

3) Mengukur dimensi benda uji menggunakan kaliper.

4) Meletakkan benda uji pada mesin uji desak yang diletakkan secara vertical untuk uji desak dengan cara peletakan secara simetris.

5) Nyalakan mesin uji desak dengan tekanan yang dinaikkan secara berangsur-angsur dengan kecepatan $0.05 \% /$ menit tiap detik.

6) Pembebanan dilakukan sampai benda uji tidak kuat lagi menahan tekanan dan retak atau hancur.

\section{PEMBAHASAN}

\section{A. Perhitungan Desain Beton}

Penelitian ini merupakan studi eksperimen yang dilaksanakan di Laboratorium, dalam pelaksanaan eksperimen ini peneliti menggunakan Laboratorium Teknik Sipil Universitas Bandar Lampung. Pengujian kuat tekan beton dilakukan dengan compression machine 15.kbs.2088 dengan kapasitas 150 ton sampai kondisi beton uji rusak. Untuk memperjelas penyajian hasil penelitian, berikut ini akan diuraikan ringkasan hasil pengujian dari material penyusun beton, dan hasil kuat tekan beton. Metode yang dipakai dalam penelitian ini adalah metode SNI 032834-2000. Hasil perhitungan perancangan proporsi beton dengan tahapan metode SNI tersebut dapat dilihat di bawah ini : 
Tabel 2. Tabel Perhitungan Perancangan Proporsi Beton

\begin{tabular}{|c|c|c|}
\hline$N_{0}$ & [nias & Nai \\
\hline & 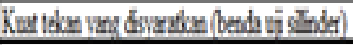 & 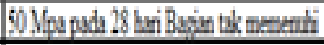 \\
\hline & Deivis Sundr & $1,7 \mathrm{Nga}$ \\
\hline 3 & 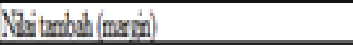 & $1,64 \times 1,7=2788$ \\
\hline 4 & 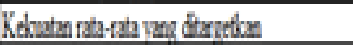 & $50+2788=52.788 \mathrm{Mga}$ \\
\hline 5 & Jenis semm & Iivet I \\
\hline & Jenis agtegt & \\
\hline 6 & bass & Bas Pecanh \\
\hline & thes & Godisillni \\
\hline 1 & Foldx in semen bettos & 0.36 \\
\hline 8 & 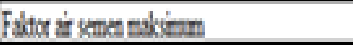 & \\
\hline 9 & $\operatorname{Sim}$ & $30.60 \mathrm{~m}$ \\
\hline 10 & Uhra agerteskimm & $D=$ \\
\hline 11. & Kadr in betes & $210 \mathrm{~K} \mathrm{sm}^{3}$ \\
\hline 12. & Kader seum & $2100,0,36=50,3,33 \mathrm{Kem}^{3}$ \\
\hline 13 & Kadr semen mbsimm & \\
\hline 14 & Koder seuten minimm & \\
\hline 15 & 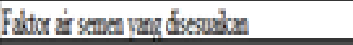 & \\
\hline 16 & Susma besar bot azerat hats & Dacah raddas sosman bets? \\
\hline 17 & 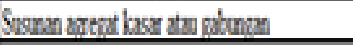 & . \\
\hline 18 & Persen areat hibs & 346 \\
\hline 19 & 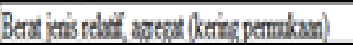 & $2019 \%$ \\
\hline D. & Beresisbettion & $2400 \mathrm{~kg}=\mathrm{m}$ \\
\hline 21 & 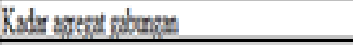 & $2400,583,39 \cdot 210=1606665 \mathrm{kgm} 3$ \\
\hline 2. & Kadr aresenthes & 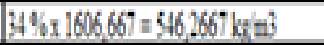 \\
\hline 23 & Kadr areag bay & $1606,667,5462.2667=1060.4 \mathrm{kgm}^{3}$ \\
\hline ta & Propersi campras: & \\
\hline & Atr & $210 \mathrm{kgm}$ \\
\hline 24 & $S_{\operatorname{sem}}$ & $563,39 \mathrm{kgm} 3$ \\
\hline & - Agegathasar & $546,2660 \mathrm{~kg}=3$ \\
\hline & - Areathats & $1060.4 \mathrm{kgm} 3$ \\
\hline & Faltor Korás: & \\
\hline & As & $196,294 \mathrm{kgm}$ \\
\hline 35 & Seman & $93,39 \mathrm{kgmi}$ \\
\hline & - Agegatlas & $10723995 \mathrm{~kg}$ \\
\hline & Arezthess & $6628185 \mathrm{ktm} 3$ \\
\hline
\end{tabular}

Pada tabel di atas didapat proporsi berat per meter kubik beton, yaitu air sebesar $196,294 \mathrm{~kg} / \mathrm{m} 3$, semen $583,33 \mathrm{~kg} / \mathrm{m} 3$, agregat halus $562,8185 \mathrm{~kg} / \mathrm{m} 3$. Untuk berat per meter kubik agregat kasar sebesar 1072,595 kg/m3 akan dijadikan landasan dasar pengambilan proporsi abu batu.

\section{B. Kuat Tekan Beton}

Pengujian kuat tekan beton dilaksanakan setelah benda uji silinder telah berumur 7 hari. Hasil pengujian kuat tekan beton rata-rata dengan berbagai variasi penggantian sebagian agregat kasar terhadap abu batu menggunakan beton dengan diameter $15 \mathrm{~cm}$ dan tinggi $30 \mathrm{~cm}$ serta pengkonversiannya terhadap umur 28 hari dengan nilai konversi 0,65 dan faktor reduksi alat 0,5 $\mathrm{T}$ dapat dilihat pada Tabel 3 . berikut ini :

Tabel 3. Hasil Perhitungan Kuat Tekan Karakteristik Rata-rata Konversi 28 Hari Untuk Setiap Variasi Campuran

\begin{tabular}{|c|c|c|c|c|c|c|}
\hline $\begin{array}{l}\text { Kadar } \\
\text { Abu } \\
\text { Batu }\end{array}$ & $\begin{array}{c}\text { Kode } \\
\text { Sampel }\end{array}$ & $\begin{array}{c}\text { Berat } \\
\text { Benda } \\
\text { 매 } \\
\text { (Ko) }\end{array}$ & $\begin{array}{c}\text { Hasil } \\
\text { Pembebanan } \\
\text { Alat (T) }\end{array}$ & $\begin{array}{c}\text { Kuat Tekan } \\
\text { Beton } 7 \text { hari } \\
\text { settlah } \\
\text { directassi } \\
\text { oleh faktor } \\
\text { reduksi alat } \\
(\mathrm{kg} / \mathrm{cm} 2)\end{array}$ & $\begin{array}{c}\text { Kuat Tekan } \\
\text { Kotressi } 28 \\
\text { Hari } \\
\left(\mathrm{Kg} \mathrm{gm}^{2} \mathrm{~cm}\right)\end{array}$ & $\begin{array}{c}\text { Kuat tekan } \\
\text { karakteristik } \\
\text { rata-rata per } \\
\text { rariasi } \\
\text { campuran } \\
\text { abu bata } \\
\text { (kg cm2) }\end{array}$ \\
\hline \multirow{5}{*}{10} & A1 & 12,8 & 50 & 290,1126998 & 430,9426151 & \multirow{5}{*}{380,4483289} \\
\hline & $A 2$ & 12,6 & 44 & 246,1596453 & 378,7071456 & \\
\hline & $\mathrm{A}^{3}$ & 12,75 & 40 & 257,4773302 & 396,1189695 & \\
\hline & $\mathrm{A} 4$ & 12,65 & 34 & 189,5712211 & 291,6480325 & \\
\hline & A5 & 12,8 & 47 & 263,1361726 & 404,82489099 & \\
\hline \multirow{5}{*}{20} & $\mathrm{~B} 1$ & 13,05 & 53 & 297,0892271 & 457,0603494 & \multirow{5}{*}{425,7190653} \\
\hline & B2 & 12,7 & 47 & 263,1361726 & 404,8248009 & \\
\hline & B3 & 1285 & 49 & 274,4538574 & 422,2367037 & \\
\hline & BA & 129 & 50 & 280,1126998 & 430,9426151 & \\
\hline & B5 & 12,65 & 48 & 268,795015 & 413,5307923 & \\
\hline \multirow{5}{*}{30} & $\mathrm{Cl}$ & 12,65 & 45 & 251,8184877 & 387,4130581 & \multirow{5}{*}{451,8368025} \\
\hline & $\mathrm{C} 2$ & 13,1 & 58 & 325,3834392 & 500,5899065 & \\
\hline & $\mathrm{C}_{3}$ & 1295 & 53 & 297,0892271 & 457,0603494 & \\
\hline & $\mathrm{CA}$ & 13 & 55 & \begin{tabular}{|l|}
308,4069119 \\
\end{tabular} & 474,4721722 & \\
\hline & C5 & 12,8 & 51 & 285,7715423 & 439,6485266 & \\
\hline \multirow{5}{*}{40} & $\mathrm{Dl}$ & 129 & 53 & 297,0992271 & 457,0603494 & \multirow{5}{*}{427,4602506} \\
\hline & D2 & 12,65 & 4 & \begin{tabular}{|l|l|}
246,1596453 \\
\end{tabular} & \begin{tabular}{|l|}
378,7071466 \\
\end{tabular} & \\
\hline & D3 & 1295 & 80 & 290,1126998 & 430,9426151 & \\
\hline & D4 & 12,8 & 51 & 285,7715423 & 439,6485266 & \\
\hline & Ds & 12,85 & 50 & 290,1126998 & 430,9426151 & \\
\hline \multirow{5}{*}{50} & E1 & 12,75 & 47 & 263,1361726 & 404,8248099 & \multirow{5}{*}{423,977886} \\
\hline & E2 & 12,65 & 46 & \begin{tabular}{|l|}
257,4773302 \\
\end{tabular} & 396,1189695 & \\
\hline & E3 & 128 & 51 & 285,7715423 & 439,0485266 & \\
\hline & EA & 12,7 & 47 & 263,1361726 & 404,8248909 & \\
\hline & ES & 12,85 & 55 & 308,4069119 & 474,4721722 & \\
\hline
\end{tabular}

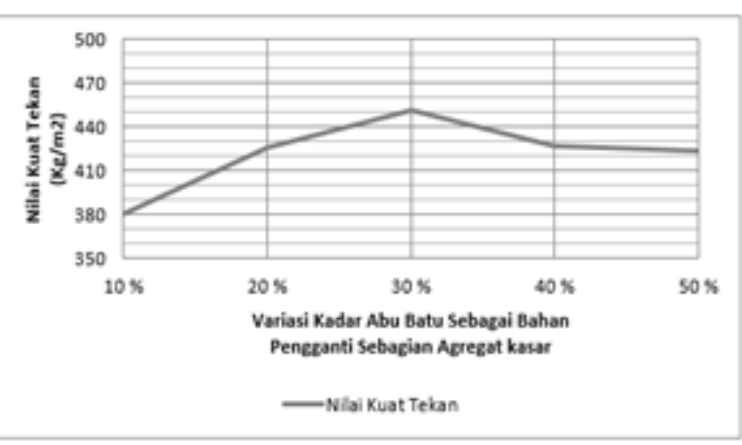

Gbr. 3 Grafik Nilai Kuat Tekan Karakteristik Rata-rata Konversi 28 Hari Untuk Setiap Variasi Campuran Abu Batu 
Dari hasil test uji tekan beton antara beton yang menggunakan abu batu sebagai bahan pengganti sebagian agregat kasar dengan berbagai variasi, menunjukkan bahwa kuat tekan rata-rata benda uji yang menggunakan abu batu sebagai bahan pengganti sebagian agregat kasar meningkat hingga variasi abu batu $30 \%$ dan kemudian menurun. Dengan adanya abu batu yang mampu menyerap air dengan baik sehingga kekentalan beton meningkat dan beton menjadi padat dan mengurangi kesempatan terjadinya segregasi dan bleeding. Tetapi pada variasi $40 \%$ dan 50 $\%$ abu batu tidak lagi memperkuat, tetapi justru mengurangi kuat tekan maksimumnya di variasi $30 \%$. Hal ini disebabkan karena kadar abu batu yang terlalu banyak sehingga air terserap lebih banyak dan mengurangi kualitas hidrasi semen yang pada keadaan ini memerlukan kadar semen dan air lebih banyak serta menggangu stabilitas dan kualitas gradasi agregat.

Berdasarkan hasil pengujian kuat tekan yang telah dilakukan nilai kuat tekan optimum pada variasi C2 yaitu beton yang menggunakan abu batu sebesar 30\% dengan kuat tekan sebesar $58 \mathrm{MPa}$, kuat tekan rataratanya lebih tinggi dibanding beton yang menggunakan variasi abu batu sebesar $10 \%$, $20 \%, 40 \%$ dan $50 \%$. Dari hasil pengujian kuat tekan rata-rata beton diketahui bahwa beton uji terbesar pada variasi abu batu $30 \%$ sebagai pengganti sebagian agregat kasar dapat meningkatkan kuat tekan beton dibanding dengan variasi $10 \%$ sebesar $18,76 \%$. Dan pada variasi $50 \%$ kuat tekan menurun sebesar $6,17 \%$ dari variasi $30 \%$.

\section{Perbandingan f'cr Rencana dan f'cr Hasil \\ Penelitian}

Pada penelitian ini menentukan f' cr rencana rata-rata laboratorium sebesar sebesar $50 \mathrm{MPa}$ sedangkan f'cr lapangan berturut turut untuk variasi abu batu sebagai pengganti sebagian agregat kasar 10\%, 20\%, 30\%, 40\%, 50\% adalah 31,58 Mpa, 35,33 Мpa, 37,5 Mpa, 35,48 Mpa, 35,19 Mpa. Dengan melihat hasil uji coba sebelum dan sesudah uji kuat tekan, dan dengan melihat hasil kuat tekan yang meningkat, dapat diambil asumsi bahwa dengan perhitungan proporsi kuat tekan beton yang ada kuat tekan beton normal maksimal akan berada di bawah kuat tekan rata-rata dari beton variasi $10 \%$ abu batu dan memiliki perbedaan kuat tekan yang jauh di bawah kuat tekan rencana melebihi $10 \mathrm{Mpa}$. Hal ini disebabkan karena kualitas dan proporsi perhitungan beton yang kurang sempurna. Dapat diambil kesimpulan bahwa perhitungan proporsi untuk kuat tekan yang direncanakan kurang baik dan kualitas material yang kurang memadai. Bagaimanapun, kuat tekan beton terus meningkat seiring pertambahan kadar abu batu hingga $30 \%$ dan kembali menurun pada variasi $40 \%$ dan $50 \%$. Hal ini terjadi karena abu batu sebagai bahan pengganti sebagian semen dapat menjadi bahan pengental beton dan filler yang baik dengan kadar maksimal $30 \%$.

Disamping kandungan bahan yang mengandung silika, bentuk tekstur dan kekuatan dari abu batu sangat berpengaruh dalam beton. Namun pada variasi campuran abu batu $40 \%$ dan $50 \%$, kuat tekan menurun. Hal ini disebabkan bahwa abu batu telah mengisi rongga-rongga pada beton pada kadar $30 \%$, sehingga sisa abu batu dalam beton tidak mempunyai fungsi lain yang mendukung naiknya kuat tekan. Dengan naiknya kebutuhan semen akibat bertambahnya luas permukaan agregat, abu batu pada kondisi dimana kadar semen tetap, berpengaruh kepada gradasi agregat secara kesuluruhan yang menyebabkan turunnya kuat tekan beton.

\section{KESIMPULAN}

\section{A. Kesimpulan}

Setelah diadakan pembuatan benda uji, perawatan benda uji dengan penyiraman, pengujian kuat tekan untuk silinder beton, serta analisis yang telah dilakukan, akhirnya penelitian ini dapat diambil beberapa kesimpulan sebagai berikut : 
1) Perhitungan proporsi beton normal dengan kuat tekan rencana yang tinggi yang telah dilakukan tidak mencapai target karena tidak didukung oleh kualitas material yang memadai dan proses pengerjaan yang kurang efektif.

2) Semakin besar variasi kadar abu batu sebagai pengganti sebagian agregat kasar berbanding lurus dengan berkurangnya nilai slump. Hal ini dapat dilihat dari hasil perhitungan nilai slump untuk setiap sampel. Hasil rata-rata dari setiap variasi campuran berturut-turut untuk $10 \%, 20 \%$, $30 \%$, $40 \%$, dan $50 \%$, adalah $8,5 \mathrm{~cm} ; 6,25$ $\mathrm{cm} ; 4,25 \mathrm{~cm} ; 3,5 \mathrm{~cm}$; dan 2,5 cm. Hasil ini terjadi karena semakin besar kadar abu batu yang dapat menyerap air lebih tinggi dari agregat lainnya menyebabkan kadar air pada campuran beton semakin berkurang dan adukan semakin mengental.

3) Hasil perhitungan rata-rata berat volume yang didapat mencapai nilai maksimal pada variasi campuran abu batu $30 \%$ dimana mencapai 2433,96 Kg/m3. Sedangkan pada variasi campuran $10 \%$ dan $50 \%$ berturutturut adalah 2400,00 Kg/m3 dan 2405,66 $\mathrm{Kg} / \mathrm{m} 3$.

4) Hasil perhitungan kuat tekan karakteristik rata-rata konversi 28 hari untuk variasi campuran $10 \%$ adalah $380,45 \mathrm{Kg} / \mathrm{m} 2$. Hasil ini meningkat seiring pertambahan kadar abu batu hingga menyentuh nilai maksimal di kadar abu batu $30 \%$ yang mencapai nilai $451,84 \mathrm{Kg} / \mathrm{m} 2$. Kuat tekan kembali menurun setelah kadar abu batu melebihi $30 \%$ dan berakhir pada kadar 50 $\%$ dimana mencapai nilai 423,98 Kg/m2.

5) Variasi campuran abu batu sebagai pengganti sebagian agregat kasar bekerja baik sebagai filler dan bahan pengental beton secara maksimal pada kadar $30 \%$ berat abu batu ditinjau dari berat volume maksimal, gradasi agregat yang paling stabil dan kuat tekan tertinggi pada variasi kadar campuran abu batu tersebut.

6) Variasi campuran abu batu sebagai pengganti sebagian agregat kasar dengan kadar di atas $30 \%$ menurunkan berat volume, kualitas gradasi agregat dan kuat tekan beton karena kadar abu batu yang terlalu banyak dan telah melewati porsi maksimal untuk menjadi filler sehingga sisa abu batu yang tidak berfungsi mengisi rongga beton merusak kualitas gradasi agregat dan memperbesar luas permukaan agregat yang harus di ikat semen.

7) Proses pengujian kuat tekan beton tidak efektif karena tidak ditempeli mortar sehingga benda uji tidak menerima pembebanan secara merata.

8) Variasi campuran beton pada penelitian ini secara keseluruhan tidak mencapai kuat tekan rencana.

\section{B. Saran}

Untuk penyempurnaan hasil penelitian serta untuk mengembangkan penelitian lebih lanjut disarankan untuk melakukan penelitian dengan memperhatikan hal - hal sebagai berikut :

1) Untuk pengembangan dan modifikasi dari penelitian ini abu batu dapat digunakan sebagai bahan pengganti sebagian agregat halus dengan kadar campuran variasi yang sama atau berbeda. Bahan yang digunakan harus berkualitas dan teruji dengan baik. Ketelitian campuran proporsi beton (mix design) serta ketelitian dalam penimbangan bahan sangat menentukan kualitas beton yang dihasilkan.

2) Pemilihan bahan campuran terutama abu batu dilakukan lebih seksama dengan melihat gradasi yang lebih halus dan berat jenis yang tinggi.

3) Pada saat akan dilakukan pengecoran atau pencampuran, agregat yang telah dicuci dan dikeringkan secara alami harus benar-benar dalam keadaan SSD sehingga kandungan air dalam agregat terjaga dan stabil.

4) Pada saat dilakukannya pengecoran, diperhatikan dengan baik sehingga beton yang ada benar-benar homogen. Pada saat penuangan beton segar ke dalam benda uji, pemadatan dilakukan dengan cepat sehingga didapat beton yang benar-benar padat. 
5) Pada saat pengujian kuat tekan, diusahakan semua permukaan benda uji diratakan dengan mortar atau melakukan capping pada kedua sisi sehingga permukaan atas dan bawah benar-benar rata dan benda uji dapat dengan baik menerima pembebanan. Perawatan benda uji sebaiknya dilakukan dengan car perendaman.

\section{REFERENSI}

[1] Edward G.Nawy. 1998. Beton Bertulang, Penerbit PT. Refika Aditama, Bandung.

[2] Mulyono ,Tri. 2005. Teknologi Beton, Penerbit Andi,Yogyakarta.
[3] Murdock JL; Brook KM; Stephanus Hendarto.1981. Bahan dan Praktek Beton, Edisi keempat Erlangga

[4] Tjokrodimuljo, K. 1996. Teknologi Beton. Buku Ajar, Jurusan Tenik Sipil, Fakultas Teknik, Universitas Gajah Mada.

[5] SNI. 2000. Tata Cara Pembuatan Rencana Campuran Beton Normal, SNI 03-2834-2000. Departemen Pemukiman dan Pengembangan Wilayah, Jakarta.

[6] Veganita, Rahmi Febria, 2012, Pengaruh Perbedaan Gradasi Pada Agregat Kasar dan Agregat Halus Alami Lokal Sungai way Balak Kota Agung Terhadap Kuat Tekan Beton. Bandar Lampung 